rev.relac.int.estrateg.segur.9(2):49-76,2014

\title{
LAS RELACIONES INTERNACIONALES DE LA GUERRA CIVIL SIRIA: ESTADOS UNIDOS Y RUSIA EN LA LUCHA POR EL PODER INTERNACIONAL"
}

\section{Rafat Ghotme ${ }^{* *}$ Alejandra Ripoll ${ }^{* * *}$}

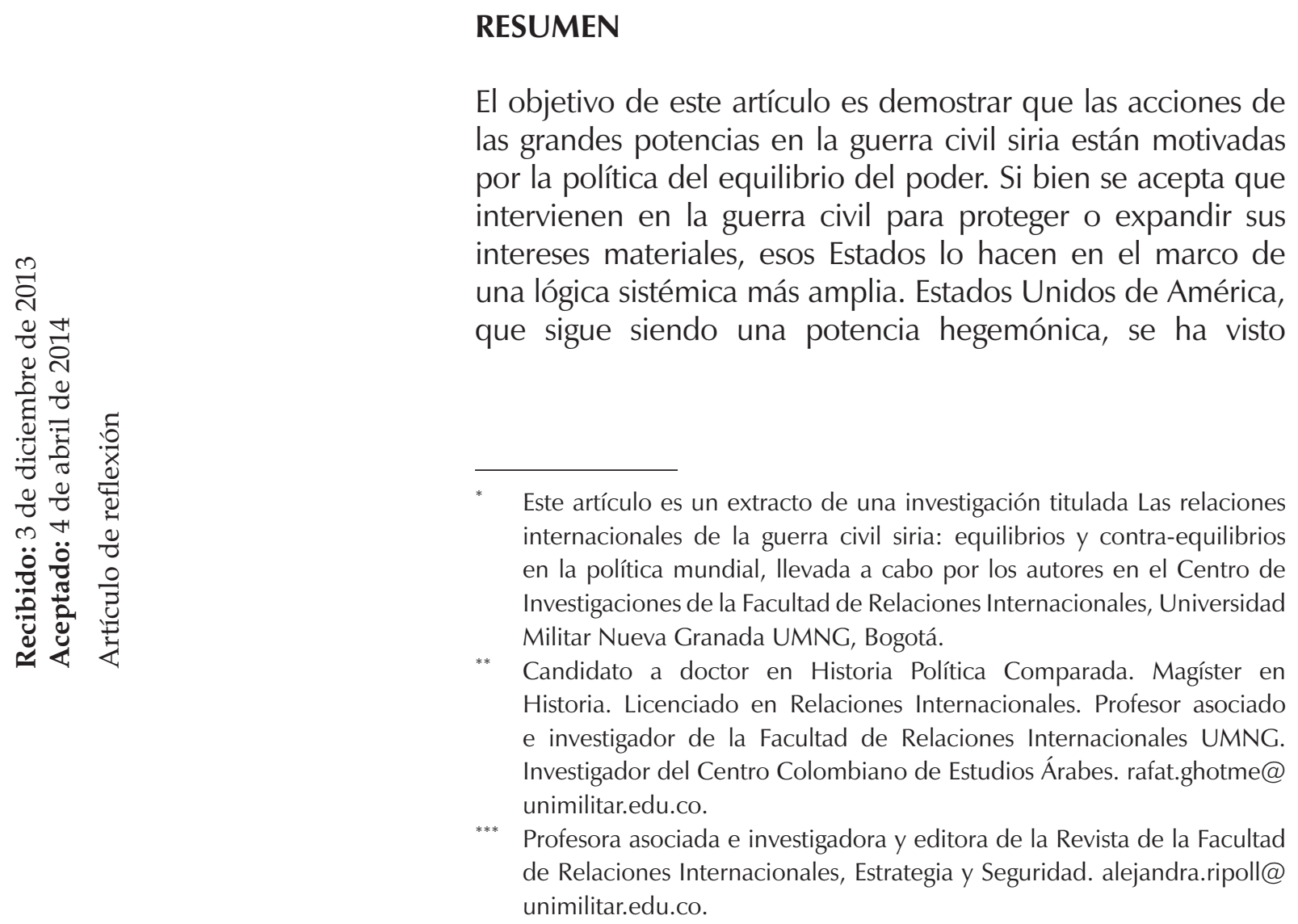


enfrentado al descenso de sus capacidades de poder, llevándolo a aceptar un nuevo statu quo -el acuerdo ruso-norteamericano- en el que tiene que sostener su propia idea de orden regional compartiendo esa función con Rusia y en menor medida con China e Irán. Ante el cambio en la distribución de poder que se está fraguando en el Medio Oriente y en el sistema internacional, esos Estados se vieron compelidos a aceptar que la política del equilibrio era la mejor alternativa.

Palabras clave: Siria, guerra civil, Estados Unidos, Rusia, China, equilibrio del poder, hegemonía.

\title{
INTERNATIONAL RELATIONS OF THE SYRIAN CIVIL WAR: THE UNITED STATES AND RUSSIA IN THE STRUGGLE FOR INTERNATIONAL POWER
}

\begin{abstract}
The aim of this article is to demonstrate that the actions of the great powers in the Syrian civil war are motivated by balance of power politics. Though it is accepted that they get involved in the civil war to protect or expand their material interests, those states do so in the context of a broader systemic logic. The United States of America, which continues being an hegemonic power, has been facing a decline in its power capabilities, leading it to accept a new status quo -the Russian-American agreement- in which it has to admit its own idea of regional order sharing that function with Russia and to a lesser extent with China and Iran. With the change in the distribution of power that is brewing up in the Middle East and the international system, those states were compelled to accept that the balance policy was the best alternative.
\end{abstract}

Keywords: Syria, civil war, United States, Russia, China, balance of power, hegemony

\section{AS RELAÇÕES INTERNACIONAIS DA GUERRA CIVIL SÍRIA: ESTADOS UNIDOS E RÚSSIA NA LUTA PELO PODER INTERNATIONAL}

\section{RESUMO}

O objetivo deste artigo é demonstrar que as ações das grandes potências na guerra civil síria são motivadas pela política do equilíbrio do poder. Embora se aceite que intervenham na guerra civil para proteger ou expandir seus interesses materiais, esses Estados fazem isso no âmbito de uma lógica sistêmica mais ampla. Os Estados Unidos da América, que ainda são uma potência hegemônica, vêm se enfrentando ao declínio de suas capacidades de poder, levando-os a aceitar um novo status quo -o acordo russo-americano- no qual têm que manter sua própria ideia de ordem regional partilhando esse papel com a Rússia, em menor grau, com a China e o Irã. Diante da mudança na distribuição do poder que está se forjando no Oriente Médio e no sistema internacional, esses Estados foram obrigados a aceitar que a política do equilíbrio foi a melhor alternativa.

Palavras-chave: Síria, guerra civil, Estados Unidos, Rússia, China, equilíbrio do poder, hegemonia. 


\section{INTRODUCCIÓN}

Estados Unidos y Rusia han intervenido en la guerra civil siria a través de diversos mecanismos diplomáticos y estratégicos; por un lado, el presidente Obama ha recurrido a medidas intervencionistas moderadas a favor de los rebeldes, mientras que Rusia ha apoyado política y diplomáticamente al gobierno sirio. Otras potencias, como China, han actuado defendiendo al régimen sirio en el marco del Consejo de Seguridad de la ONU.

Las relaciones internacionales de la guerra civil siria han estado dominadas por dos versiones explicativas. Por un lado están los "realistas liberales", a la cabeza del presidente Obama, que colocan en el mismo nivel las consideraciones humanitarias y de seguridad, manifestando que los Estados Unidos tenían la obligación, debido a su posición hegemónica mundial, de garantizar el orden y la aplicación del derecho internacional (ver el discurso de Obama en The Washington Post, 2013). La actitud de Rusia y China pueden ser denominada "soberanista": al defender enérgicamente la soberanía siria, no solo lo hacen promoviendo la visión de un orden mundial estado-céntrico, sino pensando en que el cambio de régimen en Siria podría reavivar el terrorismo y vulnerar flagrantemente el derecho internacional (ver la misiva de Putin, en The New York Times, 2013).

Sin embargo, tanto el enfoque intervencionista liberal como la soberanista tienen dos problemas fundamentales: el primero es que al colocar las normas o principios -que deben compaginar con fines altruistas o el respeto a las reglas internacionales- en el mismo nivel que los intereses materiales o de seguridad, desconocen que las normas están adecuadas a una lógica de la consecuencia. De acuerdo con esta lógica, los actores internacionales -Estados y hombres de Estado- adaptan las normas internacionales a sus intereses y, en general, con los de la "nación", utilizando para ello una estrategia racional sustentada en las capacidades de poder con las que cuentan, de modo tal que puedan preservar sus intereses (Nalbandov, 2009, p.24).

La perspectiva de los intereses materiales es correcta, aunque incompleta. El segundo error, por tanto, consiste en dejar el análisis de los intereses individuales fuera de un marco más amplio de la política internacional. Este tipo de interpretaciones es simplemente reduccionista, siendo explícitamente el caso de los intervencionistas (hegemónicos) liberales el más ilustrativo. Debido a que Estados Unidos ha sido la gran potencia hegemónica desde el fin de la guerra fría, tal posición ha llevado a diversos académicos a sostener que el momento unipolar actual va a perdurar por muchos años más y a generar ciertas condiciones para desalentar cualquier intento de equilibrio (Nye, 2010; ver el debate en Keohane, 2012). De acuerdo con esta representación del sistema internacional, la gran ventaja de poder duro y blando, junto a la naturaleza liberal del sistema político norteamericano, vuelve inefectiva la política del equilibrio de las potencias por el gran costo que conlleva una eventual equiparación con los Estados Unidos.

Ese tipo de explicaciones, limitada a los intereses de un Estado dominante o al nivel de la política interna, prescinde de varios aspectos que son relevantes para entender las interacciones de los 
Estados en el sistema internacional: primero, los Estados están preocupados por las señales de inseguridad que emanan de la anarquía internacional, independientemente de cuál sea su tipo de régimen. Estados Unidos, de hecho, como cualquier otra hegemonía, se ha visto enfrentado a un imperativo estructural del sistema internacional: las hegemonías producen respuestas contra-hegemónicas y, al mismo tiempo, se enfrentan de manera cíclica a los efectos de la sobreexpansión imperial. En segundo lugar, los Estados interactúan en el sistema internacional teniendo en cuenta los cambios en las posiciones relativas de poder (Waltz, 2000; Mearsheimer, 2001) ${ }^{1}$.

Ahora bien, estas condiciones estructurales tampoco serían suficientes para explicar los intereses individuales de cada una de las potencias que intervienen en la guerra civil siria si no se toman en consideración las capacidades relativas de poder del Estado y las alternativas que consideran los hombres de Estado para tomar una decisión racional de acuerdo con los cálculos elaborados por ellos (Lobell, Ripsman y Taliaferro, 2009). Por tanto, para superar el reduccionismo atrás denunciado, se debe adecuar el estudio de los intereses de los Estados en un marco de comprensión que abarque tanto las condiciones sistémicas como la forma en que los Estados se adaptan o actúan frente a esas condiciones, de acuerdo con sus percepciones y capacidades de poder.

A partir de este esquema, en este artículo se intentará demostrar que las acciones de las grandes potencias en la guerra civil siria están motivadas por la política del equilibrio del poder $^{2}$. Específicamente, se sostendrá que las decisiones del presidente Obama están limitadas por los imperativos sistémicos (los cambios en la distribución del poder en el Medio Oriente), pero que la política que adoptó (apoyo a los rebeldes y el acuerdo con Rusia) es el resultado de una de las diversas alternativas que compaginaban con las capacidades (en descenso) ${ }^{3}$

1. A través de una estrategia epistemológica que permita interrelacionar el efecto de las guerras civiles en la política internacional -o a la inversa-, se sostendrá que los terceros Estados tienen motivos "realistas" que los llevan a participar en la pacificación de un conflicto. Los intereses son de tipo defensivo y ofensivo. En el primer caso se trata de promover la estabilidad, proteger los intereses del Estado mediador y prevenir que una potencia rival expanda su influencia; los intereses ofensivos consisten en aumentar o expandir la influencia de la gran potencia, y recibir la gratitud de los demás Estados por rehacer la estabilidad en la región, en Zartman y Touval (1996, pp.445-461); Gibbs (2000).

2. En este estudio se concibe el equilibrio del poder como una política de resistencia u oposición que Ilevan a cabo los Estados para contener a una -potencial- hegemonía. Existen tres tipos de equilibrio: a. equilibrio "duro" o "clásico", según el cual los Estados incrementan sus capacidades de poder material o forman alianzas entre sí; b. equilibrio "suave" o "diplomático", donde los Estados forman alianzas tácitas o formales, esencialmente definidas por ser ententes de seguridad temporales o limitadas; esta forma de equilibrio también se basa en la "acumulación" limitada de armas y la cooperación o colaboración en instituciones internacionales; y c. el equilibrio "asimétrico", estrategias que utilizan los Estados para contener las amenazas "indirectas" de actores no estatales, tales como la instrumentalización de las organizaciones "terroristas" (el mejor balance en Paul, 2004).

3. Estados Unidos sigue siendo el poder dominante en el sistema internacional, y desde hace varias décadas ha implementado diversas medidas para mantener esa posición: ventaja militar sobre sus competidores, un sistema de alianzas y presencia militar en diversas zonas con un alto valor estratégico; control de rutas energéticas; dominio o 
y el sostenimiento de los intereses materiales de Estados Unidos en esa región. Dicho en otras palabras: Obama escogió conscientemente la política del equilibrio del poder ${ }^{4}$. Una consideración similar cabe para los hombres de Estado de Rusia y China: la defensa de una política de no intervención sobre Siria está relacionada con la idea de presentarse a sí mismos como actores globales cuyos intereses deben ser tenidos en cuenta, esto es, preservar su "idea" de orden o agenda regional en el Medio Oriente y en general en el sistema internacional. Al resistirse a los Estados Unidos, y expandir sus intereses, tanto Rusia como China buscan controlar zonas de influencia relevantes que afectan su seguridad y la de sus aliados, preservar la posición de poder adquirido, mantener cierto nivel de prestigio, controlar los recursos energéticos, el dominio de sus rutas y los contratos comerciales. Tomados en conjunto, estos factores nos permiten pensar que los Estados involucrados en la guerra civil siria se han visto compelidos hacia la política del equilibrio: sostener sus posiciones relativas de poder para gestionar sus intereses en un entorno anárquico.

influencia del sistema económico mundial y otras instituciones internacionales, e intenta prevenir la aparición de serios desafíos a su hegemonía global (Jackson, 2011). Sin embargo, la posición hegemónica de Estados Unidos ha descendido, mientras aumentan las capacidades de otros Estados. Si bien el Medio Oriente ha sido prioritario para el presidente Obama, la Gran Estrategia de Estados Unidos durante su gobierno se ha enfocado en el Asia Pacífico, y particularmente para hacer frente al ascendente poder chino -aunque también a Rusia, Brasil, Turquía, entre otros-. Ante la perspectiva del nuevo mundo multipolar, los Estados Unidos han tenido que enfrentarse a diversas crisis: su PIB ha descendido, al igual que su participación como productor y exportador en el mercado mundial; China superó a los Estados Unidos, y representa el 18 o 19\% de la producción manufacturera mundial, y va a equiparar el PIB de Estados Unidos hacia el año 2015 (en un 15\%). El desastre fiscal, la inflación futura y la incapacidad para pagar sus deudas "ponen en peligro la condición de Estados Unidos como país con la moneda de reserva mundial" (Layne, 2012). El descontento generalizado de los ciudadanos norteamericanos ante esta crisis interna se ha complementado con el rechazo al intervencionismo de Estados Unidos en el mundo.

4. Diversos autores sostienen que el presidente Obama ha implementado la estrategia del "equilibrio extraterritorial" (offshore balancing) en Siria (cfr. Feaver, 2013). Conceptualmente, esta estrategia tiene dos características: 1. una hegemonía regional busca convertirse en el eje equilibrista de esa región, o evitar que surja una nueva hegemonía; y 2. debido a la pesada carga de mantener una política de dominación global -lo que conlleva el declive de las capacidades de la potencia hegemónica, inestabilidad y mayor rivalidad con las grandes potencias-, la potencia hegemónica evita una intervención directa para defender sus intereses, aunque normalmente interviene recurriendo a sus aliados locales o por medio de su fuerza aérea o marítima, sin involucrar sus tropas en el terreno(Mearsheimer, 2001, p.42; Layne, 2012).El "equilibrio extraterritorial", en síntesis, es una estrategia diseñada para sostener la hegemonía de los Estados Unidos en Europa, el Medio Oriente y Asia Pacífico a muy bajos costos (Walt, 2011). Al tomar en cuenta esas premisas, es acertado concebir la política de Obama como un intento de "equilibrio extraterritorial" en la medida en que ha evitado un involucramiento directo en el terreno, manteniendo cierto nivel de apoyo a los rebeldes y buscando evitar que surja una hegemonía en la región. Sin embargo, al concebir la política de Obama de esa forma, surgen varios problemas: Estados Unidos ya no es la potencia hegemónica en el Medio Oriente que pueda preservar el equilibrio, ya que comparte esa posición con Rusia, Irán y, en menor medida, con China; además, el declive de las capacidades norteamericanas no ha ayudado a generar un frente común entre sus propios aliados, que compiten por expandir sus propios intereses a través de la guerra civil siria, algo que no ayuda mucho a generar un frente común para contener a Rusia e Irán. 


\section{LA PRIMAVERA SIRIA}

La guerra civil siria se enmarca en un proceso de reformas frustrados desde la guerra civil de 1979-1982 hasta los intentos fallidos de reformas del presidente Bashar al-Assad en la última década. Dos variables específicas desembocaron en la «primavera» de 2011: el descontento de las clases trabajadoras rurales sunitas contra la burguesía urbana, principalmente chiita, que incluía, sin embargo, un sector de la burguesía sunita y cristiana aliada al régimen; tanto las clases rurales como un sector de la clase media urbana educada, en ese sentido, manifestaron su descontento contra un régimen que se puede caracterizar de neo-patriarcal y neo-patrimonial ${ }^{5}$ (Lund, 2013a; Shehadi, 2013; al-Abdeh, 2012; Stacher, 2011).

Aunque el carácter socio-económico de la "primavera" siria sigue siendo preponderante, la espiral de violencia de 2012 y 2013 ha estado marcada por los bombardeos selectivos de ambos bandos a poblaciones enteras de sunitas o el odio encarnizado contra las fuerzas chiitas del régimen. La habitual represión a la que estaba acostumbrado el régimen derivó en una respuesta armada que inicialmente involucraba a sectores de la oposición minoritaria no sunita, pero tanto la táctica represiva del régimen como el carácter profundamente sunita de la rebelión, hizo que gradualmente la guerra civil estuviera marcada por el sectarismo (Lund, 2013a). El carácter sectario queda demostrado en la geografía política del conflicto, en el que el repliegue de los rebeldes se ha dado en las regiones sunitas (Homs, Hama, Alepo, Latakia, entre otras provincias), mientras que la costa mediterránea, dominada por los chiitas alawitas, aparece, al igual que las villas cristianas y Damasco, prácticamente sin movimientos de violencia.

Aparte de la población no armada que salió a protestar a las calles -y que aún sigue saliendo tímidamente-, y de la oposición legal en el Parlamento, en el conflicto sirio existen dos tipos de actores político-militares: el primero de ellos es el que aquí se denominará oposición secular. El segundo puede ser llamado oposición islamista. Todos estos grupos tienen en común un objetivo, esto es, el derrocamiento o cambio de régimen que preside al-Assad; en el terreno, sin embargo, los distintos actores se caracterizan por la falta de unidad, y pueden aparecer "divididos según sus lealtades o defecciones dependiendo del grado de apoyo" que se prestan los centenares de grupos y milicias entre sí y entre estos y los actores extranjeros (Martini, York y Young, 2013).

La oposición secular está dominada políticamente por la Coalición Nacional - CN, y militarmente por el Consejo Militar Supremo Conjunto de Comandos (en adelante Consejo

5. El término neo-patriarcal hace referencia a un tipo de régimen autocrático donde las decisiones se restringen a un pequeño número de hombres (el partido de gobierno), y la sociedad civil no cuenta con instituciones para ejercer control sobre el Estado. El término neo-patrimonial hace referencia al aspecto económico de las autocracias. Esta situación se resume en que las elites del poder concentran la riqueza entre un grupo reducido de parientes o círculos cercanos leales (ver Hammoudi, 2007; Harabi, 1988; para el caso sirio, ver Álvarez-Ossorio, 2009).

LAS RELACIONES INTERNACIONALES DE LA GUERRA CIVIL SIRIA: ESTADOS UNIDOS Y RUSIA EN LA LUCHA POR EL PODER INTERNACIONAL 
Militar Supremo o CSM). Operando desde el exilio (en Qatar), la CN consta de varias decenas de grupos opositores: el Consejo Nacional Sirio, la Hermandad Musulmana, la Declaración por los cambios democráticos, los comités de Coordinación Local (básicamente los civiles en el terreno), la Comisión General de la Revolución Siria (que abarca 40 grupos), los kurdos y, en general, diversos líderes tribales. Aunque inicialmente el Ejército Libre Sirio aglutinara a un importante número de desertores y milicianos reclutados en el terreno, esta organización militar terminó siendo absorbida por el CSM, liderado por el general Salim Idriss, y si bien este y el liderazgo de la CN no han firmado una alianza formal, en el terreno el CSM opera como el brazo militar de la CN. El Consejo Supremo Militar comanda más de 900 unidades militares y alrededor de 300.000 combatientes (Atassi y Haddad, 2013), pero estos, a pesar de seguir manifestando lealtad al CSM y de seguir actuando bajo su bandera, reciben una insignificante ayuda financiera y apoyo militar, por lo que muchos de esos grupos operan virtualmente independientes entre sí, o terminan abrazando la bandera de los islamistas.

Los grupos islamistas están divididos en dos vertientes. Los yihadistas vinculados a Al-Qaeda, y los yihadistas del Frente Islámico Sirio y el Frente Islámico de Salvación Sirio. Estas vertientes tienen en común una ideología islamista similar (salafista) que reivindica un Estado islámico depurado de influencias extranjeras o seculares, y ambos cooperan regularmente para combatir a las fuerzas gubernamentales. Sin embargo, los grupos afiliados a Al-Qaeda (el Frente alNusra y Al-Qaeda en Irak, este último desvinculado de Al-Qaeda central en enero de 2014) promueven una agenda islamista global ${ }^{6}$ alejada del discurso de los clérigos salafistas de Qatar, Arabia o Egipto. En cambio, los salafistas-yihadistas no vinculados formalmente a Al-Qaeda se caracterizan por tener una base local, filiaciones tribales y un discurso más moderado y pragmático. Lo que más distingue a estos grupos, por tanto, es que cuentan con una agenda estrictamente nacional. Estos movimientos son financiados y apoyados por clérigos exiliados o radicados en los países del Golfo, o musulmanes que hacen donaciones en las mezquitas u organizaciones islámicas en diversos lugares del mundo, una situación que compagina con el hecho de que los Frentes Islámicos, al tener una agenda nacional, no generan temores a los Estados que los apoyan -Qatar, Kuwait, Emiratos, Arabia y sus socios occidentales- como el que les genera Al-Qaeda (Lund, 2013b; International Crisis Group, 2013; Hassan, 2013; Black, 2013; BBC News, 2013a) ${ }^{7}$.

6. Es preciso aclarar que el Frente al-Nusra tiene una agenda local, esto es, la creación de un Emirato en Siria. Sin embargo, al jurar fidelidad a Al-Qaeda, automáticamente incorpora dos objetivos "globales" en su programa: la inmersión de Siria en un futuro Califato islámico, y la "liberación" de las influencias extranjeras.

7. En el terreno, sin embargo, Arabia y Qatar apoyan distintas agrupaciones, situación que refleja la competencia de intereses entre ambos. Arabia, por ejemplo, apoya, arma y financia a diversos grupos seculares del CSM, y otros movimientos islamistas moderados no afiliados a la Hermandad Musulmana o a Al-Qaeda, como el Frente Islámico recreado en noviembre de 2013. En cambio, Qatar apoya a los grupos islamistas cuya ideología es afín a la Hermandad, y otros grupos que tienen vínculos "informales" con Al-Qaeda. 
REVISTA DE RELACIONES INTERNACIONALES, ESTRATEGIA Y SEGURIDAD

\section{LA DIPLOMACIA DE LAS GRANDES POTENCIAS}

Las grandes potencias han intervenido en la guerra civil siria a través de dos tipos de mecanismos: la diplomacia multilateral y las medidas unilaterales. Con relación a la diplomacia multilateral, los Estados han recurrido especialmente a dos instancias: las conferencias de paz -denominadas Ginebra I y Ginebra II- y el Consejo de Seguridad de la ONU. Esos escenarios han vislumbrado el choque de los distintos tipos de preferencias de los Estados involucrados, que van desde el apoyo a una transición política que incluya al presidente al-Assad, hasta las amenazas de sanciones, cambio de régimen e intervenciones militares.

En octubre de 2011 se hizo un primer intento en el Consejo de Seguridad de la ONU para emitir una resolución sancionatoria contra Siria; en febrero y julio de 2012 se efectuaron otros dos intentos, y el último de ellos a fines de agosto de 2013, tras el supuesto uso de armas químicas por parte del régimen sirio. Esas propuestas de resoluciones estuvieron respaldadas por los Estados Unidos, Gran Bretaña, Francia y algunos otros socios occidentales y árabes (The Guardian, 2011; Mac Farquhar y Shadid, 2012; Gladstone, 2012; Swaine y Blair, 2013).

Si bien las resoluciones sancionatorias no lograron prosperar por falta de acuerdo, en medio de esas tentativas, en abril de 2012, el Consejo de Seguridad logró ponerse de acuerdo por primera vez -mediante la Resolución 2042- para abordar el problema de la creciente violencia en Siria: se establecía el desplazamiento de 30 observadores militares y se pedía al gobierno que retirase sus fuerzas de seguridad de las ciudades para emprender un plan de paz. Ese mismo mes fue aprobada la Resolución 2043, que establecía la Misión de Supervisión de Naciones Unidas para Siria, cuya duración sería de 90 días y estaría conformada por 300 observadores civiles bajo el mando del observador militar, el mayor general Robert Mood. Incrementada la violencia en Siria, el general Mood renuncia a su cargo, y el Consejo de Seguridad -a través de la Resolución 2059- extiende por 30 días más la Misión con la esperanza de que pueda llevar a cabo su misión (Sharp y Blanchard, 2013; Masters, 2013). Con ese fin se asignó a Kofi Annan como Enviado Especial de la ONU y la Liga Árabe, pero tras su renuncia -también producida por la decepción que le ocasionó su visita a Siria-, Lakhdar Brahimi asumió esa labor para implementar los seis puntos del proceso de transición que elaborara Annan con el respaldo de Rusia y algunos Estados árabes ${ }^{8}$. Con el fracaso ante sí, las medidas de Naciones Unidas se han limitado desde entonces a elaborar informes de derechos humanos, a convocar conferencias para buscar una salida política y a gestionar la ayuda humanitaria (como en la Conferencia de Kuwait de enero de 2013, en la que se esperaba recaudar unos 1.500 millones de dólares) (BBC News, 2013b).

8. Este plan contenía lo siguiente: 1. Apertura de un proceso político que incluya las aspiraciones y preocupaciones del pueblo sirio. 2. Cese de todo tipo de violencia y de todas las partes vigilado por Naciones Unidas. 3. Garantías al acceso de la ayuda humanitaria. 4. Liberación de los presos políticos encarcelados de forma arbitraria. 5. Libertad para el trabajo de los periodistas en todo el país. 6. Respeto de las autoridades a libertad de asociación y manifestación pacífica (El País, 2012).

LAS RELACIONES INTERNACIONALES DE LA GUERRA CIVIL SIRIA: ESTADOS UNIDOS Y RUSIA EN LA LUCHA POR EL PODER INTERNACIONAL 
En junio de 2012 se llevó a cabo una reunión en Ginebra -llamada posteriormente Ginebra I-, en la que el Grupo de Amigos de Siria ${ }^{9}$ llamaba a un plan de transición pacífico auspiciado por la ONU. Esta comunicación se hizo considerando que cualquier acuerdo debía hacerse por consenso, con el fin de que Rusia y China pudieran respaldar esa iniciativa; a pesar de que algunos opositores sirios estaban divididos acerca de si al-Assad debía ser parte de esa transición, el secretario Kerry no dejó lugar a dudas: "efectuar un gobierno de transición con el consentimiento mutuo de ambas partes..., significa claramente que, a nuestro juicio, el presidente Assad no será un componente de ese gobierno de transición" (citado en Sharp y Blanchard, 2013, p.9). Finalmente, tanto Rusia como Estados Unidos acordaron convocar una nueva conferencia para el verano de 2013, Ilamada Ginebra II (que se postergó para noviembre y que finalmente fue aplazada para enero de 2014). Ahora bien, la oposición secular armada ha manifestado que solo asistiría a esa conferencia si los Estados Unidos cumplían con hacer efectiva la entrega de ayuda letal, algo que no se verificaría sino hasta varios meses después (solo a medias) ${ }^{10}$. El hecho de que el régimen sirio haya recuperado terreno a mediados de 2013 en la batalla de al-Qusayir (con la ayuda de milicianos de Hizbullah y la Guardia Revolucionaria Iraní), hizo ilusoria cualquier iniciativa para convocar la conferencia ${ }^{11}$. Como se verá más adelante, el uso de dispositivos químicos entre abril y agosto de 2013 endureció la actitud norteamericana, y solo su amenaza de una intervención volvió a colocar sobre la mesa la posibilidad de convocar nuevamente la conferencia de Ginebra.

Hasta ese momento, las medidas diplomáticas multilaterales no habían logrado forzar a alAssad a aceptar una solución negociada de la crisis. Sin embargo, Estados Unidos intentó aislar al régimen sirio a través de diversos tipos de medidas unilaterales: entre abril y agosto de 2011 implementó un conjunto de sanciones -reducción de las exportaciones, congelamiento de activos, sanciones a altos funcionarios (Masters, 2013)-. Tras exigir a al-Assad en octubre de 2011 que abandonara el poder, Obama, en febrero de 2012, anunció la suspensión de las relaciones diplomáticas con Damasco (Uckman y Sly, 2011; Robinson, 2012; Shadid, 2012). Rusia intentaba mientras tanto disuadir a los rebeldes sirios, y convocó diversas reuniones con algunos de sus líderes (Lazareva, 2011; Hill, 2013). Esta fachada política ha sido trivial si se compara con el hecho de que Rusia ha prestado un apoyo diplomático invaluable al régimen sirio, y también le ha suministrado y le seguirá suministrando armas para su defensa, que, según algunos cálculos, representa el 10\% de la venta global de armas rusas con destino a Siria, contratos que tienen un valor estimado de \$1.500 millones de dólares. Este suministro incluye

9. Los Amigos de Siria es una instancia diplomática internacional celebrada fuera del marco del Consejo de Seguridad, por los países que respaldan el cambio de régimen en Siria.

10. Ver más adelante.

11. Hizbullah anunció oficialmente en mayo de 2013 que sus milicias estaban operando en territorio sirio. A mediados de ese año los rebeldes estaban ampliando sus conquistas en el terreno, por lo que la llegada de unos 3.000 milicianos de Hizbullah se unieron a las fuerzas leales al gobierno para emprender una ofensiva y recuperar la localidad de alQusair (Gorzewski y Rojas, 2013; Nerguizian, 2013; Goodarzi, 2013). 
municiones, aviones de entrenamiento militar, sistemas de defensa aérea (los sistemas anti-aéreos S-300) y armas anti-tanques. El ministro de Exteriores ruso manifestó que esa transferencia no violaba ninguna ley internacional - de embargo-, ya que "Rusia ha vendido y firmado contratos con Siria hace mucho tiempo y está completando los suministros de equipos-sistemas antiaéreos fundamentalmente-, según los contratos ya firmados" (citado en Galpin, 2012).

Aunque la actitud rusa puede ser vista como la respuesta al apoyo que presta Estados Unidos a los rebeldes, alrededor de ello existe una lucha diplomática y estratégica para ganar terreno sobre uno u otro bando. A mediados de 2012 la entonces secretaria de Estado, Hillary Clinton, y el entonces director de la CIA, David Patraeus, propusieron armar a los rebeldes con ayuda letal, propuesta a la que también se sumaría el entonces secretario de Defensa, Leon Panneta, y muchos políticos e intelectuales "intervencionistas". El presidente Obama se negó en esa ocasión, pero respaldó el envío de ayuda no letal a los rebeldes ${ }^{12}$. Paralelamente, en agosto, Obama manifestó que no toleraría que el régimen sirio atravesara la "línea roja", esto es, que al-Assad o sus hombres utilizaran dispositivos químicos contra la oposición o los civiles, y que en caso de hacerlo los Estados Unidos se reservarían el derecho para tomar las medidas que fueran necesarias; si bien esta era la primera vez que amenazaba directamente con el uso de la fuerza contra el régimen sirio, en realidad el tipo de intervención en la que estaba pensando el presidente Obama no era precisamente la que deseaban los rebeldes, los aliados árabes y la ultraderecha israelí, es decir, en una intervención militar masiva y directa (cfr. Landler, 2012) ${ }^{13}$.

La oposición secular, sin embargo, reclamaba un mayor involucramiento de la "comunidad internacional". Tanto el temor de que las armas cayeran en manos de los islamistas más radicales, como la necesidad de marginar a la Hermandad Musulmana de la coalición opositora en el exilio, Ilevaron a Estados Unidos, en la Cumbre de Doha de noviembre de 2012, a "ayudar" a unificar a la oposición "facilitando" la creación de la CN y el CSM, reconociendo al primero como el "representante legítimo del pueblo sirio" -una organización que aún no es reconocida por Damasco, ni los rebeldes islamistas en el terreno y que no ha sido bien vista por Rusia (AlJazeera, 2012; Dohertyy el Gamal, 2012; Sanger, 2012; Borger y Weaver, 2012)-. Con esa medida Estados Unidos esperaba canalizar mejor la ayuda que requerían los rebeldes seculares.

Poco después de llegar al cargo de secretario de Estado, John Kerry anunció en febrero que iba a enviar un nuevo paquete de ayuda no letal a los rebeldes con el fin de incrementar las capacidades y la credibilidad de estos. Hasta esa fecha, la promesa de ayuda norteamericana

12. La ayuda no letal a la oposición incluye suministros médicos, alimentos, equipos de comunicaciones y capacitación; también se estima que la CIA ha dado ayudas que "incluye herramientas para eludir la censura en internet, tales como software de anonimato y de satélites móviles con capacidades GPS" (Sharp y Blanchard, 2013, p. 7).

13. Ver la entrevista de Obama donde manifiesta que no tenía la intención de intervenir directamente, en Foery Hughes (2013); y Tapper (2013). 
ascendía a unos $\$ 250$ millones de dólares, a la que se adicionarían otros $\$ 100$ millones en mayo; tras anunciar en junio un programa de asistencia a los rebeldes a través de la CIA -armamento ligero, entrenamiento en Jordania, logística e inteligencia-, los estrategas de la Casa Blanca lograron convencer al Congreso en julio para que aprobara este paquete que, según el general Martin Dempsey, debía incluir una modificación en el presupuesto de la CIA de unos \$500 millonesde dólares (algo insignificante, si se compara con los 3.500 millones queha aportado el diminuto emirato qatarí) (De Young, 2013a, 2013b; Sharp y Blanchard, 2013, p.8) ${ }^{14}$.

A partir de abril de 2013 comenzó a profundizarse la preocupación estadounidense sobre el uso de armas químicas en Siria. Entre mayo y junio, de hecho, el presumible uso de armas químicas por parte del régimen sirio llevó a que Estados Unidos y Europa levantaran el embargo a algunas zonas controladas por los rebeldes, y que el presidente Obama emitiera el referido anuncio de armarlos con armas letales. Sin embargo, el ataque químico que más enfureció al presidente Obama fue el que se registró el 21 de agosto. Obama no solo estaba preocupado por la cada vez más crítica situación humanitaria en Siria, sino por los avances del ejército leal tras la batalla de al-Qusayir de junio de 2013 (North, 2013). Esta situación lo llevaría a amenazar con una intervención militar limitada y directa contra las instalaciones químicas del gobierno (lo cual se puede tomar como un cambio momentáneo de política, ya que esa intervención no estaba destinada a suscitar el cambio de régimen). La operación de castigo debía ser corta y no debía involucrar ningún soldado en el terreno (CBS News, 2013). A Obama le preocupaba, sin embargo, la gran oposición del público norteamericano, y que su compañero de aventuras bélicas -esto es, Gran Bretaña- no pudiera respaldarlo tras un bloqueo humillante del Parlamento. Bloqueado además en el Consejo de Seguridad, el presidente Obama decidió recurrir a una táctica "peligrosa": solicitó al Congreso la aprobación de la intervención militar. Mientras tanto, el 4 de septiembre el secretario Kerry anunció un reforzamiento de la ayuda letal a los rebeldes, y durante dos semanas tanto Kerry como Obama realizaron un incisivo lobby para conseguir el apoyo que requerían en el Congreso, en Europa y con los siempre dispuestos aliados árabes (BBC News, 2013c).

Una vez que la Casa Blanca presentó su solicitud al Congreso, aduciendo que el uso de armas químicas era una "obscenidad moral" -para usar las palabras de Kerry- que iba en contra del Derecho Internacional, la estabilidad y la seguridad regional, Putin advirtió que iba a seguir

14. Diversas voces han criticado el plan de ayuda a los rebeldes. Tanto los comités de inteligencia del Senado y la Cámara criticaron las "operaciones encubiertas" por el estancamiento de la ayuda dirigida al Consejo Supremo Military por las dudas que generaba la capacidad de la CIA para controlar los flujos de armas (Hosenball y Stewart, 2013). Los rebeldes, por su parte, han manifestado que Estados Unidos no ha enviado nada digno de mención; algunos comandantes rebeldes vinculados con el CSM han manifestado estar cada vez más frustrados por la falta de ayuda externa y han amenazado con romper filas y unirse a los grupos islamistas radicales (Fahrenthold y Kane, 2013; Sowell, 2013).Ahora bien, los Estados Unidos han retrasado o entregado una ayuda insignificante por temor a que caigan en manos de los rebeldes afiliados a Al-Qaeda (Entous y Malas, 2013). 
apoyando militar y diplomáticamente a al-Assad. El mensaje que parecía enviarle Putin a Obama era el siguiente: "Para nosotros, hoy, Siria representa lo mismo que representa Israel para vosotros" 15 . Putin no solo enviaba mensajes desafiantes, sino misivas a través de la prensa norteamericana, presentándose como el campeón mundial de la paz (Putin, 2013; Fisher, 2013; RT, 2013a, 2013b).

Cuando el mundo se preparaba para un supuesto ataque norteamericano contra Siria, el secretario Kerry anunció -inconscientemente- en una rueda de prensa en Londres que había una luz para Siria, introduciendo dudas sobre los planes de ataque: "Seguro que sí", dijo, "podría entregar todas y cada una de sus armas químicas a la comunidad internacional la semana próxima -entregarlas todas y sin retraso-, pero no lo va a hacer y además no se puede hacer". Presentadas como un lapsus, la Casa Blanca desmintió esa apreciación de Kerry. Y a pesar de que ese no fuera el caso, y de que muchos sectores de opinión insistan en que la propuesta había sido originalmente rusa (RT, 2013c), las palabras de Kerry fueron tomadas inmediatamente por la diplomacia rusa para colocarlas sobre el tapete en Damasco ${ }^{16}$.

Al-Assad aceptó rápidamente. Los días posteriores marcaron la ruta hacia una salida diplomática entre Rusia y Estados Unidos. Reunidos en Ginebra, los dos representantes de la diplomacia norteamericana y rusa, Kerry y Lavrov, respectivamente, lograron un acuerdo de seis puntos en el que Siria se comprometía a entregar y eliminar sus dispositivos químicos en el plazo de un año ${ }^{17}$. Este es el acuerdo ruso-norteamericano del 14 de septiembre de 2013. A fines de ese mes, se presentó una resolución en el Consejo de Seguridad que fue aprobada por todos sus miembros. Esa resolución no incluyó la aplicación del Capítulo VII de la Carta de Naciones Unidas, por lo que la verificación del acuerdo no cuenta con medidas coactivas. Hasta este momento, Siria ha cooperado resueltamente en su aplicación. Tomando como punto de partida el acuerdo ruso-norteamericano, se logró convocar nuevamente la Conferencia de Ginebra II (vigente desde enero de 2014), aunque la intransigencia de ambos bandos (y sus patrocinadores internacionales ${ }^{18}$ ), los avances del ejército sirio en los bastiones rebeldes de Homs y Malula, y la deslegitimación de la Conferencia por parte de los rebeldes islamistas en el terreno, hacen algo ilusorio cualquier acuerdo en el futuro inmediato.

15. Esta es la interpretación que aparecía en la edición española de al-Manar (2013).

16. Cfr. El País (2013) y Monge (2013). También se puede especular que tanto Rusia como Estados Unidos ya tuviesen esa medida planeada, y que la declaración de Kerry haya sido una imprudencia.

17. Esos puntos se pueden resumir así: los artículos sujetos a destrucción -equipamiento químico en general- serían reportados en un plazo estipulado de una semana, y para destruirlos, de acuerdo con un cronograma específico, en el plazo de un año (RT, 2013d).

18. En medio de la Conferencia de Paz en Ginebra, de hecho, el presidente Obama anunció a fines de mayo de 2014 un aumento del apoyo material y entrenamiento a la oposición secular, ver Entous (2014). Rusia, por su parte, se ha mostrado preocupada porque esas armas vulneren la seguridad regional, y en contrapartida prometió una ayuda de 240 millones de dólares a Siria (Ria Novosti, 2014; Xinhua, 2014).

LAS RELACIONES INTERNACIONALES DE LA GUERRA CIVIL SIRIA: ESTADOS UNIDOS Y RUSIA EN LA LUCHA POR EL PODER INTERNACIONAL 


\section{SIRIA ANTE LA HEGEMONÍA NORTEAMERICANA EN DESCENSO}

Siria, en términos generales, no ha estado en la órbita del poder norteamericano en el Medio Oriente. Y ese país tiene una importancia geoestratégica decisiva, no solo por ser un país clave en el proceso de paz con Israel, sino para reducir las amenazas terroristas y las que representa el eje chiita (Irán, Hizbullah, Siria). Para incorporarla al redil, Estados Unidos intentó aislar y debilitar a Siria cuando la obligó a retirarse de El Líbano en el 2004. La Ley de Responsabilidad siria, aprobada por el Congreso de Estados Unidos en el año 2003, además, colocaba a ese país como un Estado que se salía de todos los parámetros enmarcados en el "orden" liberal, la paz democrática y la lucha global contra el terrorismo que había emprendido Estados Unidos desde el año 2001. Ante la perspectiva de una intervención militar, Siria contuvo la presión de Estados Unidos permitiendo la libre circulación de "extremistas" en la frontera iraquí, destinados a combatir al invasor norteamericano. Hasta el año 2010 existía el temor en Damasco de que se tomase alguna medida coactiva contra el régimen, pero ese año, cuando ya había terminado la administración Bush, los Estados Unidos lograron un acuerdo tácito en el que al-Assad se comprometía a "vigilar" su frontera (Hinnebusch, 2009).

Ahora bien, a Estados Unidos le ha costado implementar esa estrategia. Esta situación se circunscribe en el marco general del declive estadounidense en el sistema internacional, y específicamente en el Medio Oriente ${ }^{19}$. La posición de hegemonía de Estados Unidos en esa región ha venido descendiendo desde el año 2006, proceso que ha estado marcado decisivamente por el triunfo de Hizbullah sobre Israel ese mismo año. El aislamiento internacional sirio comenzó a disiparse por el reforzamiento de la alianza con Irán (e internamente por las elites aliadas al régimen). El apoyo de Siria a Hizbullah, del que recibe la ayuda iraní a través de su territorio, junto al hecho de que esa organización lograra contener el avance israelí durante la invasión de 2006 a El Líbano, hizo que el eje chiita re-emergería fortalecido. Incluso los incondicionales aliados de los estadounidenses en la zona -Egipto, Arabia Saudita y Kuwait, por lo menos hasta antes de la primavera árabe-, comenzaron a acercarse a Siria. Hacia 2010, además, se había generado una especie de acercamiento entre Turquía, Irán y Siria (que el presidente al-Assad concebía exageradamente como una alianza tripartita), en la que Rusia aparecía como la superpotencia "benefactora" (Phillips, 2010). Mientras Turquía ha buscado expandir su influencia política y económica en el Medio Oriente, Rusia entró en escena para recuperar a su viejo aliado de la era soviética con una agenda regional que abarca diversos espacios claves de la región. En el año 2011 la "burla" de Libia -la utilización de una resolución del Consejo de Seguridad para cambiar violentamente el régimen-deterioró la confianza que tenía Moscú de sus aliados occidentales. Siria e Irán se apoyaron mutuamente para emprender proyectos de enriquecimiento de uranio, algo a lo que Rusia no se opuso del todo (Cruz, 2010).

19. Ver la nota 3 . 
El doble desastre de Irak y Afganistán ha conllevado una pesada carga fiscal y el deterioro de la imagen de los Estados Unidos en la región; la invasión a Irak, de hecho, desembocó en una "guerra fría" entre los Estados sunitas del Golfo, Israel, Turquía y Jordania, por un lado, y el eje chiita, por el otro, mientras que la barbarie sectaria entre sunitas y chiitas ha desatado una verdadera explosión de virulencia y extremismo en toda la región (Luenen, 2013) que Estados Unidos no ha podido controlar. Estados Unidos tampoco ha podido evitar que su "protegido" iraquí mantenga una posición de neutralidad benévola hacia el régimen sirio, y de hecho ha manifestado que no autorizaría el uso de su espacio aéreo para lanzar un ataque contra Siria (Press T.v., 2013). Finalmente, la pasividad o el escaso apoyo del gobierno Obama a la "primavera árabe" han contribuido a deteriorar la credibilidad de los Estados Unidos en la región (Keck, 2012).

En síntesis, al estallar la guerra civil siria diversos países -Irán, Turquía, Rusia- estaban aumentando su influencia a expensas de los Estados Unidos.

\section{LA GUERRA CIVIL Y EL SOSTENIMIENTO DE LA HEGEMONÍA}

Cuando estalla la guerra civil, el presidente Obama reasumió la tarea de debilitar o derrotar al régimen sirio; tanto la amenaza de una intervención como, sobre todo, la decisión de armar a los rebeldes, están en el marco de la estrategia más amplia tendiente a evitar perder más terreno.

La primera estrategia de Estados Unidos para contar con alguna preponderancia en el Medio Oriente está relacionada con la "recuperación del prestigio". Obama tiene muchas razones para desear ese resultado: su inacción entre abril y junio, cuando no tomó ninguna medida contra el régimen sirio por el supuesto uso de armas químicas, y la impopularidad de sus medidas "poco enérgicas" entre sus aliados árabes e Israel; y, finalmente, la frustración de los rebeldes por el lento y escaso apoyo que le dan los Estados Unidos, cuya inacción se ha reflejado en lo que Luttwak (2013) Ilama estrategia del "empantanamiento" o "empate indefinido" (cfr. Berger, 2013 ${ }^{20}$ ).

Aunque lento y poco prometedor, al emprender la estrategia de armar a los rebeldes o amenazar con una intervención militar directa, Obama estaba buscando un resultado favorable para sus

20. Esta estrategia consiste en mantener estancado el conflicto de modo tal que ni el régimen sirio ni los rebeldes islamistas obtengan la victoria. El "empate indefinido" lograría "mantener al Ejército de al-Assad y a sus aliados, Irán y Hizbullah, en una guerra contra combatientes extremistas alineados a Al-Qaeda", "cuatro enemigos de Washington que estarían envueltos en una guerra entre sí mismos" (Luttwak, 2013). Berger (2013), cree que esa estrategia "maquiaveliana" daría la revancha a Estados Unidos contra Siria, que en la última década permitió el paso de yihadistas a través de su frontera con Irak para reforzar a la militancia que combatía al Ejército norteamericano. 
intereses a largo plazo, esto es, preservar algo de influencia en la mesa de negociación ${ }^{21}$. Es cierto que la provisión de armamentos a los rebeldes seculares puede generar más intransigencia y más divisiones entre ellos, así como frente al gobierno. Pero es factible que las partes enfrentadas, al ser lo suficientemente fuertes como para evitar la derrota, tal situación de estancamiento podría llevarlas a evitar que se hagan daño suficiente o que se consoliden en sus áreas de dominación, de modo que ambos bandos se vean obligados a entrar en la negociación. En ese punto debe aparecer la presión de los Estados Unidos, que defenderán sus intereses en una eventual transición hacia la paz y la estabilidad. Por otra parte, el castigo al régimen de al-Assad por sus crímenes debía generar la presión suficiente para cambiar su política o poner fin a la guerra, algo que "con el tiempo ayudará a derrotar a al-Assad"; de esa forma, Estados Unidos demostrará "credibilidad ante el público extranjero y la audiencia nacional" (Seib, 2013; Badran, 2013).

El prestigio, concebido en términos realistas, está directamente relacionado con diversos tipos de consideraciones estratégicas. Tanto la seguridad como la estabilidad regional son factores que han motivado la intervención estadounidense -indirecta o directa- ante amenazas que provendrían de la posibilidad de que grupos como el Frente al-Nusra (vinculado a Al-Qaeda) adquieran armas químicas, o que el régimen no sea "castigado" por el uso de ese tipo de armas; finalmente, evitar que el eje chiita sobreviva y expanda sus actividades generando de esa forma más inseguridad sobre algunos países vecinos aliados de Estados Unidos, como Israel, Jordania y Turquía (Tabler, 2013).

Una segunda consideración estratégica debe ser tenida en cuenta, y quizás puede ser la más importante para entender cuál es el fin último de la política norteamericana en el Medio Oriente. Los fines están relacionados con dos consideraciones geopolíticas. Por un lado, debemos tomar la "cuestión iraní". Por "cuestión iraní" se hará referencia al apoyo que presta Teherán a Damasco, pero -sobre todo- a la expansión de su programa nuclear. Dicho en otras palabras: la amenaza de bombardear a Siria está dirigida en gran medida a presionar a Irán para que deshaga su programa de enriquecimiento de uranio. La consejera de Seguridad Nacional, Susan Rice, lo deja ver de manera explícita: "Esto tiene implicaciones en nuestros esfuerzos para evitar un Irán con armas nucleares. Un ataque que demuestre que Estados Unidos hace lo que dice. Que deje claro a al-Assad y sus aliados-Hizbullah e Irán- que no deje lugar a dudas la determinación de los Estados Unidos de América" (The White House, 2013). Dicho de otro modo: si Obama no "castiga" a al-Assad, podría dar alas a un Irán "peligrosamente" nuclear que generaría una nueva carrera en el Medio Oriente y más inseguridad a los aliados de Estados Unidos.

21. Como decía el congresista republicano John McCain, a principios de marzo de 2012: "cada vez más, la cuestión para Estados Unidos no es si las fuerzas extranjeras intervendrán militarmente en Siria. Podemos estar seguros de que los vecinos de Siria lo harán con el tiempo, si no lo están haciendo ya. El peligro es que estos vecinos traten de elegir a los ganadores, y esto no siempre será de nuestro agrado o de nuestro interés" (2012). 
Como se ha dicho, Obama no ha tenido interés en un ataque directo. El hecho de que Obama haya dejado a un lado las presiones para llevar a cabo el cambio de régimen en Siria se hizo en parte para evitar que Irán se vuelva más intransigente en la defensa de Damasco o que tomara medidas de represalia contra Israel en caso de que Estados Unidos atacara a Siria para impedir, en últimas, que la guerra civil siria se propague por toda la región. Al llegar a la Presidencia de Irán el islamista moderado Hassan Rouhani, Obama modificó la ecuación de la política exterior norteamericana hacia el régimen de los ayatolas: a fines de septiembre de 2013, Obama y Rouhani sostuvieron una inesperada conversación telefónica, anunciando un nuevo periodo de diálogos que concluyó con un acuerdo preliminar de seis meses -sin descartar un ataque militar contra Irán (algo que siempre está destinado a apaciguar a los israelíes) (Nuruzzaman, 2013)-.

Es verosímil que el acercamiento a Irán se deba a una estrategia calculada hacia el corto plazo, destinada a obligar a sentarse a todas las partes a negociar, como en efecto se logró con la Conferencia de Ginebra II. Pero en un nivel más amplio el presidente Obama busca deshacer o contener (equilibrarse con) el eje Rusia-Irán-Siria, e -hipotéticamente- acercar a Irán a su órbita. Irán ha representado un obstáculo permanente para la expansión de la hegemonía norteamericana en el Medio Oriente. De hecho, un eventual triunfo del eje chiita $-y$ de su cercano socio mayor, Rusia- disminuiría la preponderancia de los norteamericanos en esa región y desviaría la atención de su Gran Estrategia de contención del poderío chino y ruso en Asia o Europa Oriental ${ }^{22}$.

La segunda consideración geopolítica de Estados Unidos está relacionada con el control de las rutas energéticas. Siria no es un gran productor de petróleo. Una de sus principales características geográficas es que está ubicada en un punto crucial alrededor de países como Israel, con el que mantiene un viejo conflicto territorial por la ocupación israelí de los Altos del Golán. Aparte de ello, su importancia geoestratégica radica en que cuenta con un espacio que se puede constituir en una ruta de transporte de recursos energéticos hacia el Mediterráneo. El interés primordial de Estados Unidos es el libre flujo de los recursos energéticos, independientemente de quién los provea - una dictadura o una democracia-. Si no logra ese objetivo, Estados Unidos procura evitar que alguien tome su lugar como potencia hegemónica que garantice ese flujo -como el eje chiita, que incluye parcialmente a Irak y que puede garantizar a Rusia la promesa de no construir ningún gasoducto que rivalice con los suyos-, y si lo hace en una situación de estabilidad, utilizando para ello a sus "socios" menores, como Qatar, menos costosa sería esa política (Ahmed, 2013). Hasta el momento, sin embargo, Estados Unidos no ha podido deshacer los planes energéticos del eje Siria-Irán-Rusia.

Aunque es exagerado sostener que la "pérdida" de Siria representaría un duro golpe para los intereses de Estados Unidos en El Levante, lo que más preocupa a los defensores de la

22. En este punto, podría sugerirse una hipótesis: el anuncio hecho por Obama a fines de mayo de 2014 de armar más a los rebeldes seculares, puede estar dirigido a aumentar la presión contra Rusia por su actitud ante la crisis en Ucrania. 
hegemonía norteamericana es que Estados Unidos haya perdido la capacidad para gestionar unilateralmente el orden y la estabilidad en esa región, y que esa tarea la tenga que compartir con Rusia, Irán y, en menor medida, con China. A Obama, en ese sentido, lo han castigado drásticamente (Nichols y Schindler, 2013 a, 2013 b). En realidad, Obama escogió la mejor alternativa que le impone la nueva distribución del poder en la región: el reparto de sus tareas hegemónicas era lo máximo que podía conseguir ante la feroz resistencia de Irán, pero también de Rusia, como se verá a continuación.

\subsection{LA CARRERA HACIA EL EQUILIBRIO}

Tanto Rusia como China han defendido al régimen sirio utilizando un discurso soberanista. La aplicación del veto sobre resoluciones que buscaban sancionar o intervenir en Siria durante cuatro ocasiones fue una medida destinada a respaldar una "transición" que incluyera al-Assad, el único interlocutor legítimo según los cálculos de Moscú y Beijing.

El razonamiento chino es principalmente político y, en menor medida, económico. Si bien económicamente los vínculos con Siria son estrechos -China se ha convertido en el mayor proveedor de productos importados de Siria y sus inversiones en el sector petrolero sirio son significativas-, los chinos tienen muchas fuentes distintas a las cuales acceder y, de hecho, en la economía siria el petróleo no es un renglón importante. Por tanto, China está pensando realmente en proteger sus intereses estratégicos en el Medio Oriente. Como dice Wong (2012): "La lógica es la siguiente: dado que Siria es un estrecho aliado de Irán, al mantener intacto al régimen sirio o, más importante, prevenir la sustitución pro-occidental de este, China, de hecho, está asegurando que Irán mantenga su apoyo regional y no sea presa de otra invasión liderada por Occidente". En otras palabras, China busca preservar el eje geopolítico chiita para prevenir la expansión de Estados Unidos en el Medio Oriente y mantener estable la única zona que le puede servir para mantener su propia influencia y contener el expansionismo norteamericano hacia las zonas colindantes de China (cfr. Swaine, 2012; Sun, 2013).

Si bien los intereses chinos coinciden con los rusos, estos dos Estados no actúan de una manera totalmente coordinada ${ }^{23}$. Junto a Irán, Rusia se ha convertido en un decidido protector de alAssad. Esa actitud no obedece a una adecuación irrestricta a las normas internacionales -el respeto de la soberanía-. Aunque la "burla de Libia" (la utilización de la resolución 1973 para implementar un cambio de régimen en ese país) influyó en los cálculos de Moscú, existen diversos niveles que pueden explicar la actitud defensiva rusa. Internamente, Putin ha decidido

23. Recientemente, Rusia y China han profundizado sus relaciones. Si bien aún no han firmado una alianza militar, este nuevo acercamiento incluye la firma de un multimillonario acuerdo para suministro de gas y el impulso para la creación de nuevos mecanismos u organizaciones de defensa en conjunto con Irán, esta última propuesta surgida en el marco de la Conferencia de Interacción y Medidas de Confianza en Asia, celebrada en China, en mayo de 2014 (RT, 2014). 
silenciar a sus críticos liberales -algo que hizo con cierto paroxismo en la campaña reeleccionista de principios de 2012-, denunciando los sucesos de la primavera árabe como una conspiración occidental liderada contra los gobiernos de corte nacionalista y anti-occidentales; el asesinato de Gadafi, por ejemplo, fue condenado por Putin con un encendido discurso anti-occidental. Russell Mead (2012) ilustra lúcidamente el pensamiento de Putin, quien refleja "un clásico juego de suma cero realista en el que no se sabe si los internacionalistas liberales en Washington son tontos e ingenuos, o expertos políticos profundamente cínicos, cuyo deliberado uso de una retórica liberal ellos mismos desprecian y desdeñan para confundir a sus enemigos y conseguir el apoyo de sus victorias ante una estúpida opinión pública".

Putin desea presentarse ante la opinión pública interna y foránea como un defensor acérrimo del estado-centrismo, pero el discurso resiste todo. La obstinación rusa para sostener al régimen que encabeza Bashar al-Asad en Damasco no solo se debe a la cercanía que tiene este con Putin, sino al hecho de que Siria es un importante comprador de armas rusas, un Estado "cliente" que provee al Kremlin la única base militar en el Mediterráneo oriental (Bagdonas, 2012). Rusia, además, tiene intereses energéticos. Como dice Lazareva (2011), "A medida que la región ha desarrollado su capacidad de extracción y exportación de petróleo y gas, Rusia tenía un incentivo adicional para mantener y desarrollar las relaciones, que quiere continuar aumentando la presencia y la influencia de las empresas de energía en la región y, cuando sea posible, para mantener altos los precios del petróleo". Rusia también ha invertido en tecnología, tanto para la construcción de ferrocarriles como en la producción de alta tecnología nuclear. Una última consideración aparece en los cálculos de Moscú: el islamismo militante que opera en Siria puede propagarse a Chechenia y otros espacios rusos donde existe una importante población musulmana (Trenin, 2012; Hill, 2013). La crisis sectaria que atraviesa la región entre el chiismo y el sunismo ha sido aprovechada por Rusia para retornar al Medio Oriente. A pesar de las divisiones internas en el eje sunita, este se ha caracterizado por ser históricamente hostil a los rusos, y si bien Rusia tiene razones para apaciguar a la opinión pública sunita en su propio país (teniendo en cuenta el caso checheno), Moscú desconfía de los Estados sunitas por su apoyo a los musulmanes secesionistas de la Federación Rusa. Rusia, por tanto, ha retornado al Medio Oriente utilizando a los chiitas de la misma forma como los Estados Unidos utilizan a los sunitas (Russell Mead, 2013).

Sin embargo, la defensa de Siria y de sus intereses en el Levante se circunscribe en una más amplia dinámica de la política exterior rusa hacia el Medio Oriente. El "retorno" de Rusia, después de una ausencia casi total tras la Guerra Fría, está en directa relación con el rol que ha desempeñado históricamente en esa región; durante la era soviética sus intereses se plasmaron mediante el establecimiento de zonas de influencia gobernadas por Estados revisionistas o nacionalistas, una política que ha sido impulsada en los últimos años por los estrategas del Kremlin ${ }^{24}$. La política rusa hacia Siria se circunscribe en una dimensión sistémica: una visión de

24. Especialmente por Yevgeny Primakov desde mediados de los años 90, y recientemente por el ministro de Exteriores Serguei Lavrov (en Bagdonas, 2012). 
orden multipolar donde Rusia pueda gestionar sus intereses o convertirse en un actor influyente y, al mismo, tiempo promover la implantación de normas internacionales distintas a las que promueven los aliados occidentales ${ }^{25}$. Siria, pues, se ha convertido en el nuevo pilar de la estrategia equilibrista de Rusia en el Medio Oriente.

\section{INTERPRETACIÓN DEL ACUERDO RUSO-NORTEAMERICANO A MANERA DE CONCLUSIÓN}

El momento unipolar actual está atravesando una fase de transición. Esta lógica explica la necesidad de Estados Unidos para apoyar a los rebeldes seculares sirios o amenazar con una intervención directa para "castigar" al régimen sirio por el supuesto uso de armas químicas. Inicialmente la actitud de Obama se había manifestado abiertamente titubeante, y en diversos medios fue criticado por no tomar medidas coactivas enérgicas contra el régimen sirio. Sin embargo, el presidente Obama entendió a la perfección los límites que le imponían tanto las nuevas relaciones de fuerzas del sistema internacional como las diversas crisis internas que afrontan los Estados Unidos, reflejado en el declive de sus capacidades de poder. El acuerdo ruso-norteamericano de septiembre, y el iraní-norteamericano de noviembre de 2013, por tanto, pueden ser definidos como el reflejo de la incapacidad o la no intención de Estados Unidos para embarcarse en una nueva carrera intervencionista directa en el Medio Oriente. En otras palabras, Obama escogió la mejor alternativa ante el cambio en la distribución de poder que se está fraguando en el Medio Oriente.

El momento unipolar actual también está generando las condiciones para producir respuestas contra-hegemónicas. Si bien el resultado final se debe principalmente al descenso de las capacidades de poder de los Estados Unidos - que a pesar de ello sigue siendo una potencia hegemónica-, también influye la oposición de otros Estados hacia la política norteamericana. Rusia seguramente no hubiera transformado su apoyo militar y diplomático al régimen sirio en una oposición militar al ataque norteamericano sobre Siria, y de hecho Estados Unidos hubiera podido llevar a cabo la intervención sin ninguna oposición militar directa digna de mención por parte de Rusia o China. Pero la oposición rusa debe ser vista como una política de equilibrio que buscaba evitar la caída de uno de sus pilares estratégicos en el Medio Oriente. Tanto el descenso de las capacidades norteamericanas, como las intenciones y las políticas de Rusia, China e Irán, han llevado a aceptar un nuevo statu quo -el acuerdo ruso-norteamericano- en el que esos Estados buscan sostener su propia idea de orden regional, compartiendo las tareas de dominación, mantenimiento de la estabilidad, la seguridad e intereses; de hecho, el eje tácito construido entre Damasco, Moscú, Beijing y Teherán refleja la expansión del poder e influencia de esos países a expensas del poder norteamericano.

25. La norma que más aversión ha causado a Putin es la del intervencionismo humanitario, que cataloga como un artificio creado para justificar la expansión de los objetivos estratégicos de Estados Unidos y sus socios (en Bagdonas, 2012). 


\section{REFERENCIAS}

- $\quad$ Ahmed, N. (2013, Aug 30). Syria intervention plan fueled by oil interests, not chemical weapon concern. The Guardian. Recuperado de: http://www.theguardian.com/environment/earthinsight/2013/aug/30/syria-chemical-attack-war-intervention-oil-gas-energy-pipelines

- $\quad$ Al-Abdeh, M. (2012, March 1). How I understand the Syrian revolution. Syria in Transition blog. Recuperado de: syriaintransition.com/2012/03/01/how-i-understand-the-syrianrevolution

- Al-Jazeera (2012, Nov 11). Syrian opposition groups sign coalition deal. Recuperado de: http://www.aljazeera.com/news/middleeast/2012/11/20121111141834268537.html

- Al-Manar (2013, 14 de septiembre). Rusia e Irán a EEUU: "Siria es lo mismo para nosotros que Israel para ti". Recuperado de: http://www.almanar.com.lb/spanish/adetails. php?eid $=40875 \&$ cid $=23 \&$ fromval $=1$

- Álvarez-Ossorio, I. (2009). Siria Contemporánea. Madrid: Editorial Síntesis.

- Atassi, B. and Haddad, M. (2013, 19 Jul 2013). Interactive: Mapping Syria's rebellion. Al Jazeera examines the military and political opposition groups trying to overthrow President Bashar al-Assad. Al-Jazeera. Recuperado de: http://www.aljazeera.com/indepth/ interactive/2013/07/20137188552345899.html

- $\quad$ Badran, T. (2013, 21 de septiembre). Obama's credibility gap. Recuperado de: https:// now.mmedia.me/lb/en/commentaryanalysis/obamas-new-credibility-gap

- Bagdonas, A. (2012). Russia's Interests in the Syrian Conflict: Power, Prestige, and Profit. European Journal of Economic and Political Studies, 5(2), 55-77

- $\quad$ BBC News (2013a, dec 13). Syria crisis: Guide to armed and political opposition. Recuperado de: http://www.bbc.co.uk/news/world-middle-east-24403003

- $\quad$ BBC News (2013b, jan 30). Donors pledge \$1.5bn for UN Syria aid operation. Recuperado de: http://www.bbc.co.uk/news/world-middle-east-21258511

- $\quad$ BBC News (2013c, sep 8). Kerry meets Arab leaders to seek Syria strike support. Recuperado de: http://www.bbc.co.uk/news/world-europe-24006746

- $\quad$ Berger, A. (2013, june 22). Obama's statecraft may be a calculated, Machiavellian approach. Boston Globe. Recuperado de: http://www.bostonglobe.com/opinion/2013/06/21/the-letburn-strategy-syria/1oFemcOqylCsNs1jdJpiGL/story.html 
- Borger, J. and Weaver, M. (2012,nNov 2). West backs Qatari plan to unify Syrian opposition. The Guardian. Recuperado de: http:/www.theguardian.com/world/2012/nov/02/westbacks-qatari-plan-syria

- $\quad$ CBS News (2013, aug 31). Obama seeks Syria strike with Congress' approval. Recuperado de: http://www.cbsnews.com/news/obama-seeks-syria-strike-with-congress-approval/

- Cruz, A. (2010, 27 de mayo). Siria logra una nueva correlación de fuerzas en Oriente Próximo. Web Islam. Recuperado de: http://www.webislam.com/articulos/38930-siria logra_una_nueva_correlacion_de_fuerzas_en_oriente_proximo.html

- De Young, K. (2013a, apr 20). U.S. pledges to double nonlethal aid to Syrian rebels as opposition backers reach consensus. The Washington Post. Recuperado de: http://www. washingtonpost.com/world/middle_east/kerry-in-istanbul-joins-quest-for-commonground-on-aid-to-syrian-rebels/2013/04/20/896b39e6-a9d0-11e2-b029-8fb7e977ef71_ story.html

- De Young, K. (2013b, july 22). Congressional panels approve arms aid to Syrian opposition. The Washington Post. Recuperado de: http://www.washingtonpost. $\mathrm{com} /$ world/national-security/congressional-panels-approve-arms-aid-to-syrianopposition/2013/07/22/393035ce-f31a-11e2-8505-bf6f231e77b4_story.html

- Doherty, R. \& El Gamal, R. (2012, Nov 10). Syrian opposition debates forming U.S.-backed assembly. Reuters. Recuperado de: http://www.reuters.com/article/2012/11/10/us-syriadoha-talks-idUSBRE8A90C720121110

- $\quad$ El País (2012, 17 de julio). El plan de paz de Annan. Recuperado de: http://internacional. elpais.com/internacional/2012/07/17/actualidad/1342537180_156356.html

- El País (2013, 9 de septiembre). Rusia toma la palabra a Kerry y pide a Siria que rinda su arsenal químico. 2013. Recuperado de: http://internacional.elpais.com/internacional/2013/09/09/ actualidad/1378716125_349668.html

- $\quad$ Entous, A.\& Malas, N. (2013, sep. 4). Rebel Groups Still Wait For CIA Arms Supplies. Wall Street Journal. Recuperado de: http://online.wsj.com/news/articles/SB400014241278873 24202304579051280341316034

- Entous, A. (2014, may 27). Obama Close to Authorizing Military Training of Syrian Rebels. Wall Street Journal. Recuperado de:http://online.wsj.com/articles/obama-closeto-authorizing-military-training-of-syrian-rebels-1401198550?tesla $=y \& \mathrm{mg}=$ reno64wsj\&url=http://online.wsj.com/article/SB1000142405270230481190457958787220478 0320.html 
- Fahrenthold, D. \& Kane, P. (2013, sep. 3). On Syria, Obama Faces a Skeptical Public. The Washington Post. Recuperado de: http://articles.washingtonpost.com/2013-09-03/ politics/41726298_1_chemical-weapons-syria-missile-strike

- Feaver, P. (2013, april 30). Not even one cheer for offshore balancing? Foreign Policy. Recuperado de: http://shadow.foreignpolicy.com/posts/2013/04/30/not_even_one_ cheer_for_off_shore_balancing

- Fernández, Y. (2013, 20 de mayo). Las armas rusas defienden Siria. Al Manar en español. Recuperado de: http://www.almanar.com.lb/spanish/adetails.php?fromval=1\&cid=49\&fr $\mathrm{id}=49$ \&eid $=33789$

- $\quad$ Fisher, M. (2013, sep. 12). Vladimir Putin's New York Times op-ed, annotated and fact-checked. The Washington Post. Recuperado de:http://www.washingtonpost.com/blogs/worldviews/ wp/2013/09/12/vladimir-putins-new-york-times-op-ed-annotated-and-fact-checked/

- $\quad$ Foer, F. \& Hughes, C. (2013, jan. 27). Interview. Barack Obama Is Not Pleased. The president on his enemies, the media, and the future of football. New Republic. Recuperado de: http://www.newrepublic.com/article/112190/obama-interview-2013-sit-down-president

- Galpin, R. (2012, 1 de febrero). Las armas rusas cruciales para Siria. BBC Mundo. Recuperado de:http://www.bbc.co.uk/mundo/noticias/2012/02/120201_siria_rusia_armas.shtml

- Gibbs, D. (2000). Realpolitik and Humanitarian Intervention: The Case of Somalia. International Politics, 37, 41-55.

- Gladstone, R. (2012, july 19). Friction at the U.N. as Russia and China Veto Another Resolution on Syria Sanctions. The New York Times. Recuperado de: http://www.nytimes. com/2012/07/20/world/middleeast/russia-and-china-veto-un-sanctions-against-syria.html

- Goodarzi, J. (2013). Iran: Syria as the first line of defense. In J. Barnes-Dacey and D. Levy (eds.). The Regional Struggle for Syria. London: European Council on Foreign Relations.

- Gorzewski, A. \& Rojas Sasse, E. (2013, 25 de mayo). El papel de Hezbollah en la guerra civil siria. DW. Recuperado de: http://www.dw.de/el-papel-de-hezbollah-en-la-guerracivil-siria/a-16836657

- Hammoudi, A. (2007). Maestro y discípulo. Fundamentos culturales del autoritarismo en las sociedades árabes. Barcelona: Anthropos.

- Harabi, H. (1988). Neopatriarchy. A theory of Distorted Change in Arab Society. New York: Oxford University Press. 
- Hill, F. (2013, march 25). The Real Reason Putin Supports Assad. Mistaking Syria for Chechnya. Foreign Affairs. Recuperado de: http://www.foreignaffairs.com/articles/139079/ fiona-hill/the-real-reason-putin-supports-assad?page =show

- Hinnebusch, R., Kabalan, M., Kodmani, B. \& Lesch, D. (2009). Syrian Foreign Policy and the United States: From Bush to Obama. St Andrews Papers on Contemporary Syria.

- Hosenball, M., \& Stewart, P. (2013, july 8). Congress Delaying U.S. Aid to Syrian Rebels. Reuters. Recuperado de: http://www.reuters.com/article/2013/07/08/us-usa-syria-armsidUSBRE96713N20130708

- International Crisis Group (2013, oct 17). Anything But Politics: The State of Syria's Political Opposition. Middle East Report, 146. Recuperado de: http://www.crisisgroup.org/ / media/Files/Middle\%20East\%20North\%20Africa/Iraq\%20Syria\%20Lebanon/Syria/146anything-but-politics-the-state-of-syrias-political-opposition.pdf

- Jackson, R. (2011, july 11). The World's Most Warring Nation. E-International Relations. Recuperado de: http://www.e-ir.info/2011/07/02/the-world\%E2\%80\%99s-most-warringnation/

- Keck, Z. (2012, july 3). Realism and the Arab Spring. Does America really want a democratic Middle East? The Majalla. Recuperado de: http://www.majalla.com/eng/2012/07/ article55232816

- Keohane, R. (2012). Hegemony and After: Knowns and Unknowns in the Debate Over Decline. Foreign Affairs, 91 (4), 114-118.

- Landler, M. (2012, aug 20). Obama Threatens Force Against Syria. The New York Times. Recuperado de: http://www.nytimes.com/2012/08/21/world/middleeast/obamathreatens-force-against-syria.html

- Layne, C. (2012, january 27). The (Almost) Triumph of Offshore Balancing. The National Interest. Recuperado de: http://nationalinterest.org/commentary/almost-triumph-offshorebalancing-6405

- Lazareva, I. (2011, dec 22). Putin, Medvedev and the Arab Spring: will Russia's foreign policy end up on the wrong side? Open Democracy. Recuperado de: http://www.opendemocracy. net/od-russia/inna-lazareva/putin-medvedev-and-arab-spring-will-russias-foreign-policyend-up-on-wrong-s

- Luenen, C. (2013, sep26). Time for a U.S. Middle EastU-Turn. The National Interest. Recuperado de: http://nationalinterest.org/commentary/time-us-middle-east-u-turn-9136?page=show 
- Lund (2013a). Freedom fighters? Cannibals? The truth about Syria's rebels. The Independent. Recuperado de: http://www.independent.co.uk/news/world/middle-east/freedomfighters-cannibals-the-truth-about-syrias-rebels-8662618.html

- Lund, A. (2013b). Syria's salafi insurgents: The rise of the Syrian Islamic Front. UI Ocasional Papers. Swedish Institute of International Affairs, 17. Recuperado de: www.ui.se

- Luttwak, E. (2013, aug 24). In Syria, America Loses if Either Side Wins. The New York Times. Recuperado de: http://www.nytimes.com/2013/08/25/opinion/sunday/in-syriaamerica-loses-if-either-side-wins.html?_r $=0$

- MacFarquhar, N. \& Shadid, A. (2012, feb 4). Russia and China Block U.N. Action on Crisis in Syria. The New York Times. Recuperado de: http://www.nytimes.com/2012/02/05/ world/middleeast/syria-homs-death-toll-said-to-rise.html?pagewanted=all

- Martini, J.; York, E. \& Young, W. (2013). Syria as an Arena of Strategic Competition. Rand Corporation. Recuperado de: www.rand.org

- Masters, J. (2013, may 8). Syria's Crisis and the Global Response. Council on Foreign Relations. Recuperado de: http://www.cfr.org/syria/syrias-crisis-global-response/p28402

- McCain, J. (2012, march 6). Remarks by Senator John McCain on the Situation in Syria on the Floor of the U.S. Senate. The New Jurist. Recuperado de: http://www.newjurist.com/ remarks-by-senator-John-McCain-on-the-situation-in-syria.html

- Mearsheimer, J. (2001). The Tragedy of Great Power Politics. New York: Norton.

- Monge, Y. (2013, 9 de septiembre). El secretario de Estado sugiere que el régimen sirio ponga su arsenal químico bajo control internacional. El País. Recuperado de: http://internacional. elpais.com/internacional/2013/09/09/actualidad/1378742060_848327.html

- Nalbandov, R. (2009). Battle of two Logics: Appropriateness and Consequentiality in Russian Interventions in Georgia. Caucasian Review of International Affairs, 3 (1), 20-36.

- Nerguizian, A. (2013, june 17). Assessing the Consequences of Hezbollah's Necessary War of Choice in Syria. Center for Strategic and International Studies. Recuperado de: http:// csis.org/publication/assessing-consequences-hezbollahs-necessary-war-choice-syria

- Nichols, T. \& Schindler, J. (2013a, sep 16). America's Middle East Policy Collapses. The National Interest. Recuperado de: http://nationalinterest.org/commentary/americasmiddle-east-policy-collapses-9073? page $=$ show 
- Nichols, T. \& Schindler, J. (2013b, sep 25). Obama Enabling Russia's Mideast Rise. The National Interest. Recuperado de: http://nationalinterest.org/commentary/obamaenabling-russias-mideast-rise-9128? page $=$ show

- North, D. (2013, sep 19). US Imperialism and the Proxy War in Syria. Global Research. Recuperado de: http://www.globalresearch.ca/us-imperialism-and-the-proxy-war-insyria/5352642

- Nuruzzaman, M. (2013, dec 11). The Iran Nuclear Deal - A Preliminary Analysis. E-International Relations. Recuperado de: http://www.e-ir.info/2013/12/11/the-irannuclear-deal-a-preliminary-analysis/\#_ftn8

- Nye, J. (2010). The Future of American Power: Dominance and Decline in Perspective. Foreign Affairs, 89 (6), 2-14.

- Paul, T.V. (2004). Introduction: The Enduring Axioms of Balance of Power Theory and Their Contemporary Relevance. In T.V. Paul, J. Wirtz and M. Fortmann, M. (eds.). Balance of Power: Theory and Practice in the 21st. Century. Stanford: Stanford University Press.

- $\quad$ Phillips, C. (2010, june 1). US hegemony in Middle East is ending. America-Russia.net. Recuperado de: http://www.america-russia.net/eng/security/245873652

- Press T.V. (2013, aug 26). Iraq will not allow its airspace be used in attacks on Syria. Recuperado de: http://www.presstv.ir/detail/2013/08/26/320606/iraq-airspace-not-forattack-on-syria/

- $\quad$ Putin, V. (2013, sep 11). Plea for Caution From Russia. What Putin Has to Say to Americans About Syria. The New York Times. Recuperado de: http://www.nytimes.com/2013/09/12/ opinion/putin-plea-for-caution-from-russia-on-syria.html?_r=0 A

- $\quad$ Ria Novosti (2014, may 28). Russia to Offer \$327Mln in Free Financial Aid to Syria. Recuperado de: http://en.ria.ru/russia/20140528/190186420/Russia-to-Offer-327Mln-inFree-Financial-Aid-to-Syria.html

- $\quad$ Robinson, D. (2012, aug 20). Obama Warns Syria on Chemical Weapons, Calls for Assad to Step Down. Voice of America. Recuperado de: http://www.voanews.com/content/obamaagain-calls-for-assad-departure-warns-on-chemical-weapons/1491834.html

- $\quad$ RT (2013a, 22 de septiembre). Ciudadanos de EE.UU. solicitan que Obama ceda su Premio Nobel de la Paz a Putin. Recuperado de: http://actualidad.rt.com/actualidad/ view/106523-peticion-obama-nobel-paz-putin 
- $\quad$ RT (2013b, 19 de septiembre). EE.UU. teme mostrar a Putin en la portada de la revista Time. Recuperado de: http://actualidad.rt.com/actualidad/view/106174-eeuu-timeportada-putin-rusia

- $\quad$ RT (2013c, 12 de septiembre). Rusia pareció salvar a Obama de una posible vergüenza nacional. Recuperado de: http://actualidad.rt.com/actualidad/view/105549-rusia-obamasiria-guerra-putin

- $\quad$ RT (2013d, 14 de septiembre). Los puntos claves del plan de Rusia y EE.UU. sobre las armas químicas en Siria. Recuperado de:htpp://actualidad.rt.com/actualidad/view/105706puntos-claves-plan-rusia-eeuu-siria

- $\quad$ RT (2014, 22 de mayo). China aboga por una alianza de seguridad con Rusia e Irán, "una pesadilla para EE.UU.". Recuperado de: http://actualidad.rt.com/actualidad/ view/128891-china-alianza-seguridad-rusia-iran-pesadilla-eeuu?utm_source=rss\&utm_ medium =rss\&utm_campaign $=$ actualidad

- $\quad$ Russell Mead, W. (2012, feb 5). Russia's Syrian Bet Explained. The American Interest. Recuperado de: http://blogs.the-american-interest.com/wrm/2012/02/05/russias-syrianbet-explained/

- Sanger, D. (2012, oct 14). Rebel Arms Flow Is Said to Benefit Jihadists in Syria. The New York Times. Recuperado de: http://www.nytimes.com/2012/10/15/world/middleeast/ jihadists-receiving-most-arms-sent-to-syrian-rebels.html?pagewanted=all

- $\quad$ Seib, G (2013, sep 9). Syria Credibility Gap: Where's the Risk? The President Will Argue That American Interests Are at Stake if Military Action Is Blocked. Wall Street Journal. Recuperado de: http://online.wsj.com/article/SB1000142412788732386460457906496 3818091016.html

- Shadid, A. (2012, feb 6). U. S. Embassy in Syria Closes as Violence Flares. The New York Times. Recuperado de: http://www.nytimes.com/2012/02/07/world/middleeast/violencein-syria-continues-after-diplomacy-fails.html?pagewanted=all

- $\quad$ Sharp, J. \& Blanchard, C. (2013, sep 6). Armed Conflict in Syria: Background and U.S. Response. Congressional Research Service. Federation of America Scientist. Recuperado de: https://www.fas.org/sgp/crs/mideast/RL33487.pdf

- $\quad$ Shehadi, N. (2013, may 6). Revolution or civil war? The battle of narratives in Syria. Open Democracy. Recuperado de: www.opendemocracy.net/...al-attar.../syria-revolution-orcivil-war 
- $\quad$ Sowell, K. (2013, sep 3). The fragmenting FSA. Foreign Policy. Recuperado de: http:// mideast.foreignpolicy.com/posts/2013/09/03/the_fragmenting_fsa

- Stacher, J. (2011). Reinterpreting Authoritarian Power: Syria's Hereditary Succession. The Middle East Journal, 65 (2), 197-212.

- $\quad$ Sun, Y. (2013, jan 31). March West: China's Response to the U.S. Rebalancing. Brookings Institution. Recuperado de: http://www.brookings.edu/blogs/up-front/posts/2013/01/31china-us-sun

- Swaine, J. \& Blair, D. (2013, sep 27). Syria crisis: Russia may use veto to thwart UN action against Assad. The Telegraph. Recuperado de: http://www.telegraph.co.uk/news/ worldnews/middleeast/syria/10340915/Syria-crisis-Russia-may-use-veto-to-thwart-UNaction-against-Assad.html

- Swaine, M. (2012). Chinese Views of the Syrian Conflict. China Leadership Monitor, 39. Recuperado de: http://www.hoover.org/publications/china-leadership-monitor/9581

- $\quad$ Tabler, A. (2013). Syria's Collapse and How Washington Can Stop It. Foreign Affairs, 92.

- Tapper, J. (2013, sep 10). Sen Murphy: Obama told Democrats he has 'no interest' in military strikes if he has other options. CNN. Recuperado de: http://thelead.blogs.cnn. com/2013/09/10/sen-murphy-obama-told-democrats-he-has-no-interest-in-militarystrikes-if-he-has-other-options/

- $\quad$ The Guardian (2011, oct 5). Russia and China veto UN resolution against Syrian regime. Recuperado de: http://www.theguardian.com/world/2011/oct/05/russia-china-veto-syriaresolution

- The Washington Post (2013, sep 10). President Obama's Sept. 10 speech on Syria. Recuperado de: http:/www.washingtonpost.com/politics/running-transcriptpresident-obamas-sept-10-speech-on-syria/2013/09/10/a8826aa6-1a2e-11e3-86855021e0c41964_story.html

- The White House (2013, sep. 9). Remarks As Prepared for Delivery by National Security Advisor Susan E. Rice. Recuperado de: http://www.whitehouse.gov/the-pressoffice/2013/09/09/remarks-prepared-delivery-national-security-advisor-susan-e-rice

- Trenin, D. (2012, feb 5). Russia's Line in the Sand on Syria. Why Moscow Wants To Halt the Arab Spring. Foreign Affairs. Recuperado de: http://www.foreignaffairs.com/ articles/137078/dmitri-trenin/russias-line-in-the-sand-on-syria 
- Uckman, L. \& Sly, L. (2011, aug 18). Obama: Syrian President Assad must step down. The Washington Post. Recuperado de: http://www.washingtonpost.com/blogs/ checkpoint-washington/post/obama-syrian-president-assad-must-step-down/2011/08/18/ gIQAM75UNJ_blog.html

- $\quad$ Walt, S. (2011). The End of the American Era. The National Interest, 116, 6-16.

- Waltz, K. (2000). Structural Realism after de Cold War. International Security, 25(1), 5-41.

- Wong, N. (2012, july 25). China's veto on Syria: what interests are at play? Open Democracy. Recuperado de: http://www.opendemocracy.net/nicholas-wong/china\%E2\%80\%99sveto-on-syria-what-interests-are-at-play

- Xinhua (2014, may 28). Preocupa a Rusia posible apoyo militar de EE.UU. a oposición siria. Recuperado de: http://spanish.china.org.cn/international/txt/2014-05/28/content_ 32518361.htm

- Zartman, W. \& Touval, S. (1996). International Mediation in the Post-Cold War Era. In C. Crocker, F. Hampson and P. Aall (eds.), Managing Global Chaos. Washington: United States Institute of Peace Press, pp. 445-461. 